Терапия оральными антикоагулянтами у больных с фибрилляцией предсердий в амбулаторной и госпитальной медицинской практике (данные регистров РЕКВАЗА)

Михаил Михайлович Лукьянов ${ }^{1 *}$, Сергей Юрьевич Марцевич1, Оксана Михайловна Драпкина', Сергей Степанович Якушин ${ }^{2}$, Александр Николаевич Воробьев², Кристина Геннадьевна Переверзева², Александр Васильевич Загребельный', Владимир Валентинович Якусевич³, Владимир Владимирович Якусевич ${ }^{3}$, Екатерина Михайловна Позднякова ${ }^{3}$, Татьяна Александровна Гомова ${ }^{4}$, Елена Евгеньевна Федотова ${ }^{4}$, Марат Нафизович Валиахметов 5 , Вадим Петрович Михин Юлия Вениаминовна Масленникова6, Елена Юрьевна Андреенко1, Владислав Георгиевич Кляшторный', Егор Викторович Кудряшов', Елена Юрьевна Окшина', Марина Ареслановна Панагопулу', Сергей Анатольевич Бойцов ${ }^{7}$

${ }^{1}$ Национальный медицинский исследовательский центр профилактической медицины Россия, 101000, Москва, Петроверигский пер., 10

2 Рязанский государственный медицинский университет им. академика И.П. Павлова Россия, 390026, Рязань, ул. Высоковольтная, 9

з Ярославский государственный медицинский университет

Россия, 150000, Ярославль, Революционная ул., 5

${ }^{4}$ Тульская областная клиническая больница. Россия, 300053, Тула, ул. яблочкова, 1а

5 Городская больница №3 г. Тулы. Россия, 300910 Тула, ул. Пушкина, 17

${ }^{6}$ Курский государственный медицинский университет. Россия, 305041, Курск, ул. Карла Маркса, 3

${ }^{7}$ Национальный медицинский исследовательский центр кардиологии

Россия, 121552, Москва, ул. 3-я Черепковская, 15а

Цель. В рамках регистров РЕКВАЗА оценить у больных с фибрилляцией предсердий (ФП) частоту назначения терапии оральными антикоагулянтами (ОАК) на амбулаторно-поликлиническом и госпитальном этапах и ее динамику в ходе длительного проспективного наблюдения. Материал и методы. В амбулаторные регистры РЕКВАЗА (Рязань) и РЕКВАЗА ФП-Ярославль, а также в госпитальные регистры РЕКВАЗА ФП (Москва, Курск, Тула) включено 3169 пациентов с ФП (возраст 70,9土10,7 лет, 43,1\% мужчин), у которых оценена частота назначения ОАК на госпитальном и амбулаторном этапах, в т.ч., до госпитализации и в период отдаленного наблюдения от 2 до 6 лет.

Результаты. ОАК были назначены лишь в 42,2\% случаев (1335 пациентам из 3169, возраст 69,1 1 10,4 лет, 46\% мужчин), в т.4. варфарин - 817 пациентам (26\%) и новые оральные антикоагулянты (НОАК) - 518 (16\%). Частота назначения ОАК при постоянной и персистирующей формах ФП (43\% и 40\%) была ниже, чем при пароксизмальной $(47,6 \% ;$ p <0,05), несмотря на более высокий риск тромбоэмболических

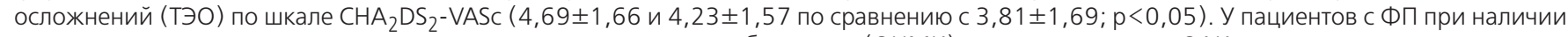
и отсутствии перенесенного острого нарушения мозгового кровообращения (ОНМК) частота назначения ОАК статистически значимо не различалась (42,5\% и 40\%; p>0,05), что совершенно не обосновано по отношению к больным, перенесшим ОНМК, и имеющим больший риск ТЭО по шкале $\mathrm{CHA}_{2} \mathrm{DS}_{2}$-VASc $(6,14 \pm 1,34$ по сравнению с $3,77 \pm 1,39 ; \mathrm{p}<0,001)$. По ретропроспективным данным Выявлено, что ОАК наиболее часто назначались на госпитальном этапе $(54,1 \%)$, т.е. в 2,3 раза выше, чем до госпитализации (23,8\%), и в 4 раза выше, чем при включении в амбулаторные регистры (13,5\%). Несмотря на снижение частоты назначения ОАК в 1,3 раза (до 41,2\%) за 2,3 $\pm 0,9$ лет после выписки из стационара, данный показатель оставался выше в 1,8 раза, чем до госпитализации. В регистре РЕКВАЗА (Рязань) по данным опроса 384 выживших пациентов за 4 года наблюдения частота назначения ОАК возросла с 4,2\% до 18,7\% (в 4,4 раза), а по результатам анализа амбулаторных карт в случайной выборке 75 человек из 297 выживших за 6 лет наблюдения - с 5,3\% до 22,7\% (в 4,2 раза).

Заключение. По данным регистров РЕКВАЗА и РЕКВАЗА ФП в 5 регионах Российской Федерации терапия ОАК назначалась больным с ФП недостаточно часто. Существенной дополнительной проблемой является то, что риск ТЭО у больных с назначением ОАК (в т.ч. варфарина и НОАК) ниже, чем у пациентов с ФП без их назначения. У больных с постоянной формой ФП, характеризующейся более высоким риском ТЭО, частота назначения ОАК ниже, чем при пароксизмальной. У пациентов с наличием и отсутствием ОНМК в анамнезе частота назначения ОАК существенно не отличалась. Выявлено значительное, хотя и недостаточное, повышение частоты назначения ОАК (преимущественно HOAK) у больных с ФП на амбулаторно-поликлиническом этапе при проспективном наблюдении длительностью от 2 до 6 лет. 
Ключевые слова: фибрилляция предсердий, регистры, терапия оральными антикоагулянтами, варфарин, новые оральные антикоагулянты, амбулаторный и госпитальный этапы лечения, проспективное наблюдение.

Для цитирования: Лукьянов М.М., Марцевич С.Ю., Драпкина О.М., Якушин С.С., Воробьев А.Н., Переверзева К.Г., Загребельный А.В., Якусевич В.В., Якусевич В.В., Позднякова Е.М., Гомова Т.А., Федотова Е.Е., Валиахметов М.Н., Михин В.П., Масленникова Ю.В., Андреенко Е.Ю. Кляшторный В.Г., Кудряшов Е.В., Окшина Е.Ю., Панагопулу М.А., Бойцов С.А. Терапия оральными антикоагулянтами у больных с фибрилляцией предсердий в амбулаторной и госпитальной медицинской практике (данные регистров РЕКВАЗА) Рациональная Фармакотерапия в Кардиологии 2019;15(4):538-545. DOI:10.20996/1819-6446-2019-15-4-538-545

\section{The Therapy with Oral Anticoagulants in Patients with Atrial Fibrillation in Outpatient and Hospital Settings (Data from RECVASA Registries)}

Mikhail M. Loukianov*, Sergey Yu. Martsevich', Oxana M. Drapkina', Sergey S. Yakushin², Alexander N. Vorobyev², Alexander N. Kozminsky², Kristina G. Pereverzeva², Alexander V. Zagrebelnyy', Vladimir Val. Yakusevich³, Vladimir Vl. Yakusevich³, Ekaterina M. Pozdnyakova ${ }^{3}$, Tatiana A. Gomova ${ }^{4}$, Elena E. Fedotova ${ }^{4}$, Marat N. Valiakhmetov ${ }^{5}$, Vadim P. Mikhin 6 , Yulia V. Maslennikova ${ }^{6}$, Elena Y. Andreenko ${ }^{1}$, Vladislav G. Klyashtorny ${ }^{1}$, Egor V. Kudryashov' ${ }^{1}$ Elena Yu. Okshina ${ }^{1}$, Marina A. Panagopulu', Sergey A. Boytsov

${ }^{1}$ National Medical Research Center for Preventive Medicine. Petroverigsky per. 10, Moscow, 101990 Russia

${ }^{2}$ Ryazan State Medical University named after Academician I.P. Pavlov. Visokovoltnaya ul. 9, Ryazan, 390026 Russia

${ }^{3}$ Yaroslavl State Medical University. Revolutsionnaya ul. 5, Yaroslavl, 150000 Russia

${ }^{4}$ Tula Regional Clinical Hospital. Yablochkova ul. 1a, Tula, 300053 Russia

${ }^{5}$ City hospital №3 of Tula. Pushkina ul. 17, Tula, 300910 Russia

${ }^{6}$ Kursk State Medical University. Karla Marxa ul. 3, Kursk, 305041 Russia

${ }^{7}$ National Medical Research Center of Cardiology. Tretya Cherepkovskaya ul. 15a, Moscow, 121552 Russia

Aim. To evaluate an incidence of oral anticoagulants (OAC) administration during longterm follow-up period in patients with atrial fibrillation (AF) enrolled in outpatient and hospital RECVASA registries.

Material and methods. 3169 patients with AF were enrolled in outpatient registries RECVASA (Ryazan), RECVASA AF-Yaroslavl and hospital registries RECVASA AF (Moscow, Kursk, Tula), age 70.9 \pm 10.7 years, $43.1 \%$ men. The incidence of OAC administration was evaluated in hospital and outpatient settings, including longterm follow-up period (2-6 years).

Results. OAC were administrated only in $42.2 \%$ of cases (1335 from 3169 patients; age $69.1 \pm 10.4$ years, $43 \%$ men), including warfarin ( 817 patients; $26 \%$ ) and non-vitamin $\mathrm{K}$ antagonist oral anticoagulants (NOAC) - $518(16 \%)$. Patients with permanent and persistant types of AF had lower incidence of OAC administration ( $43 \%$ and $40 \%$ ) than in cases of paroxysmal type $(47.6 \%, \mathrm{p}<0.05)$, despite of the higher $\mathrm{CHA}_{2} \mathrm{DS}_{2}-\mathrm{VASC}$ risk score $(4.69 \pm 1.66$ and $4.23 \pm 1.57$ vs $3.81 \pm 1.69 ; p<0.05)$. Patients with and without history of stroke received OAC in $42.5 \%$ and $40 \%$ of cases that means no significant difference $(p>0.05)$ contrary to the pronounced difference of thromboembolic risk in these groups $(6.14 \pm 1.34$ and $3.77 \pm 1.39 ; p<0.001)$. The incidence of OAC administration in hospitals $(54.1 \%)$ was 2.3 times higher than before hospitalization ( $23.8 \%$ ) and was 4.0 times higher than in outpatient registries $(13.5 \%)$. During follow-up period after hospital treatment ( $2.3 \pm 0.9$ years) this parameter decreased from $54.1 \%$ to $41.2 \%$, but was still 1.8 times higher than before admission to the hospital. After 4 years follow-up in RECVASA (Ryazan) registry we revealed 4.4 times higher incidence of OAC administration compared with enrollment data $(4.2 \%$ and $18.3 \%, p<0.0001)$. This data was confirmed by the information from outpatient medical cards of accidentally generated group ( 75 from 297 patients survived during follow-up period): $5.3 \%$ at baseline and $22.7 \%$ six years later.

Conclusions. RECVASA registries in 5 regions of Russia revealed low incidence of OAC administration. The risk of thromboembolic events was higher in patients with AF and no OAC administration compared with patients who received OAC. Patients with paroxysmal type of AF received OAC more often than those with permanent type. There were no significant differences of incidence of OAC therapy in patients with and without history of stroke. Both questioning of patients with AF and analysis of medical cards in outpatient clinics revealed higher incidence of OAC administration after 4-6 years of follow-up compared with the stage of enrollment in registries.

Keywords: atrial fibrillation, registries, therapy with oral anticoagulants, warfarin, non-vitamin $\mathrm{K}$ antagonist oral anticoagulant, outpatient and hospital settings, follow-up.

For citation: Loukianov M.M., Martsevich S.Y., Drapkina O.M., Yakushin S.S., Vorobyev A.N., Kozminsky A.N., Pereverzeva K.G., Zagrebelnyy A.V. Yakusevich V.V., Yakusevich V.VI., Pozdnyakova E.M., Gomova T.A., Fedotova E.E., Valiakhmetov M.N., Mikhin V.P., Maslennikova Yu.V., Andreenko E.Yu., Klyashtorny V.G., Kudryashov E.V., Okshina E.Y., Panagopulu M.A., Boytsov S.A. The Therapy with Oral Anticoagulants in Patients with Atrial Fibrillation in Outpatient and Hospital Settings (Data from RECVASA Registries) Rational Pharmacotherapy in Cardiology 2019;15(4): 538-545. DOI:10.20996/1819-6446-2019-15-4-538-545

*Corresponding Author (Автор, ответственный за переписку): loukmed@gmail.com

Received / Поступила: 23.07.2019

Accepted / Принята в печать: 25.07.2019

Согласно данным доказательной медицины риск тромбоэмболических осложнений (ТЭО), прежде всего, кардиоэмболического мозгового инсульта (МИ), у больных с фибрилляцией предсердий (ФП) возможно снизить, в первую очередь, благодаря использованию антикоагулянтной терапии варфарином, либо новыми оральными антикоагулянтами (HOAK), что отражено и обобщено в международных и Российских клинических рекомендациях [1-6].

Однако в реальной медицинской практике частота назначения оральных антикоагулянтов (ОАК) является недостаточной [7-10]. Одним из основных способов оценки качества медикаментозной терапии и обследования пациентов в медицинской практике являются 
регистры. По данным ряда регистров больных с ФП антикоагулянтная терапия, в Т.ч. варфарином и НОАК, в медицинской практике назначается недостаточно часто, что не соответствует в должной степени клиническим рекомендациям [11-17].

Результаты регистров РЕКВАЗА и РЕКВАЗА ФП О медикаментозном лечении больных с ФП в медицинской практике были опубликованы ранее [18-22]. В настоящем исследовании представлен обобщенный анализ данных о частоте назначения ОАК в амбулаторной и госпитальной практике в рамках регистров РЕКВАЗА в пяти регионах Российской Федерации (РФ).

Цель данного исследования - оценить у больных с ФП частоту назначения терапии ОАК на амбулаторно-поликлиническом и госпитальном этапах, и ее динамику в ходе длительного проспективного наблюдения в рамках регистров РЕКВАЗА.

\section{Материал и методы}

В рамках амбулаторных регистров РЕКВАЗА (Рязань) и РЕКВАЗА ФП-Ярославль, а также госпитальных регистров РЕКВАЗА ФП (Москва, Курск, Тула) у 3169

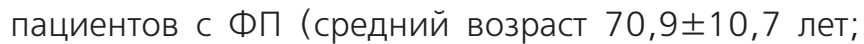
$43,1 \%$ мужчин) оценена частота назначения ОАК на госпитальном и амбулаторном этапах, в т.ч. - до госпитализации и в период отдаленного наблюдения от 2 до 6 лет.

Больные с ФП были включены в 5 городах Российской Федерации в следующие регистры: РЕКВАЗА (530 человек, обратившихся в 3 поликлиники г. Рязани в период март-май 2012 г; ; сентябрь-октябрь 2012 г. и январь-февраль 2013 г.); РЕКВАЗА ФП-Ярославль (404 человека, обратившихся в 2 поликлиники г. Ярославля за период январь-декабрь 2013 г.); РЕКВАЗА ФП-Москва (508 человек, госпитализированных в ФГБУ НМИЦПМ в апреле 2013-марте 2014 гг.); РЕКВАЗА ФП-Тула (1225 человек, госпитализированных в Тульскую областную клиническую больницу в январе-декабре 2013 г.) и РЕКВАЗА ФП-Курск (502 пациента, госпитализированных в Курскую городскую клиническую больницу скорой помощи за период июнь 2013 г.-май 2014 г.). Из 3169 больных с ФП в амбулаторные регистры (Рязань, Ярославль) были включены 934 (29,5\%) пациентов, и в госпитальные (Курск, Москва, Тула) - 2235 (70,5\%). Более подробное описание дизайна регистровых исследований было опубликовано нами ранее [18-22], а также в отдельной статье приведена детальная информация о частоте назначения варфарина и контроле показателя международного нормализованного отношения [23].

Критериями включения в исследование были:

1) Указание на диагноз ФП в амбулаторной карте, либо в клиническом диагнозе госпитальной истории болезни;
2) Назначение терапии ОАК по данным амбулаторной карты (на дату визита включения), либо в эпикризе при выписке из стационара.

Длительность проспективного наблюдения пациентов составила в регистрах: РЕКВАЗА (Рязань) 4,0 00,1 лет, РЕКВАЗА ФП-Курск - 2,5 $\pm 0,5$ лет, РЕКВАЗА ФП-Москва - 2,8 $\pm 0,6$ и РЕКВАЗА ФП-Ярославль -

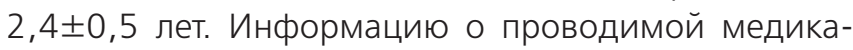
ментозной терапии на этапе отдаленного наблюдения удалось выяснить при телефонном контакте или при визите к врачу в рамках вышеперечисленных регистровых исследований: в 97,2\%; 92,8\%; 94,3\% и 96,6\% случаев, соответственно.

В рамках регистра РEKВАЗА (Рязань) в группе из 384 пациентов с ФП, выживших за период наблюдения

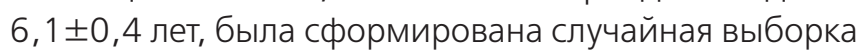
75 человек (средний возраст 70,0 $\pm 10,9$ лет, 40,0\% мужчин), у которых на основании данных амбулаторных карт была проанализирована динамика частоты назначения ОАК.

Для статистической обработки данных использовались методы описательной статистики. Статистическая значимость различий средних величин оценивалась С помощью критерия Стьюдента, статистическая значимость различий частоты наличия признаков в группах сравнения - непараметрическим методом с применением критерия хи-квадрат и теста Мак-Немара. Статистически значимыми считались различия при $p<0,05$. Статистическую обработку данных проводили с помощью компьютерных программ Statistica и SAS 9.3.

\section{Результаты}

Терапия ОАК была назначена 1335 из 3169 пациентов $(42,2 \%)$. Частота назначения ОАК у больных с ФП была недостаточной как на госпитальном этапе (у 1209 из 2235 пациентов, 54,1\%), так и, в особенности, на амбулаторном этапе (в 126 из 994 случаев, 13,5\%; табл. 1). Частота назначения варфарина (25,9\%) была в среднем в 1,6 раза больше, чем таковая для НОАК (16,3\%). При этом на амбулаторном этапе варфарин назначался в 8,7 раз чаще, чем НОАК, а на госпитальном этапе преимущественное назначение варфарина было зарегистрировано лишь в регистре РЕКВАЗА ФПТула, в то время как в регистрах РЕКВАЗА ФП-Москва и Курск чаще назначались НОАК.

Из 1834 пациентов с ФП без назначения ОАК в 96 случаях (5,2\%) на госпитальном этапе были назначены парентеральные антикоагулянты, В т.ч. 43 пациентам в регистре РЕКВАЗА ФП-Тула (8,0\% от числа больных без ОАК), а также 41 и 12 пациентам в регистрах РЕКВАЗА ФП-Курск и РЕКВАЗА ФП-Москва $(10,0 \%$ и 18,7\%, соответственно). Из этих 96 пациентов данная терапия была назначена при выписке из стационара в 22 случаях, а остальные 74 случая составили умершие 
Table 1. Prescription rate of warfarin and new oral anticoagulants in patients with atrial fibrillation included in the RECVASA registers

Таблица 1. Частота назначения варфарина и НОАК у больных с ФП, включенных в регистры РЕКВАЗА

\begin{tabular}{lccc}
\hline Региональный регистр & Варфарин & НОАК & Все ОАК \\
\hline Рязань (амбулаторный), $n(\%), n=530$ & $19(3,6)$ & $3(0,6)$ & $22(4,2)$ \\
\hline Ярославль (амбулаторный), $n(\%), n=404$ & $94(23,3)$ & $10(2,5)$ & $104(25,8)$ \\
\hline Курск (госпитальный), $n(\%), n=502$ & $46(9,2)$ & $47(9,4)$ & $93(18,6)$ \\
\hline Москва (госпитальный), $n(\%), n=508$ & $167(32,9)$ & $261(51,4)$ & $428(84,3)$ \\
\hline Тула (госпитальный), $n(\%), n=1225$ & $491(40,1)$ & $197(16,1)$ & $688(56,2)$ \\
\hline Всего больных, $n=3169$ & $817(25,9)$ & $518(16,3)$ & $1335(42,2)$ \\
\hline ФП - фибрилляция предсердий, НОАК - новые оральные антикоагулянты, ОАК - оральные антикоагулянты & & \\
\hline
\end{tabular}

в стационаре больные, преимущественно, с патологией хирургического профиля. В амбулаторных регистрах не было зарегистрировано случаев назначения парентеральных антикоагулянтов у больных с ФП.

Частота назначения ОАК у больных с различными формами ФП существенно различалась (табл. 2). Так, при постоянной и персистирующей формах ФП по сравнению с пароксизмальной формой варфарин назначался статистически значимо чаще, а НОAК - реже $(p<0,05)$. При этом назначение ОАК в целом осуществлялось у пациентов с постоянной и персистирующей формами ФП значимо реже, чем при пароксизмальной $(p=0,03$ и $p=0,006)$. У 45 пациентов с диагнозом «впервые выявленная ФП» ОАК были назначены в 6 случаях (13,3\%), а среди 113 пациентов с не указанной формой ФП назначение ОАК было осуществлено в 7 (6,2\%) случаях. Необходимо подчеркнуть, что при постоянной и персистирующей формах ФП риск тромбоэмболических осложнений (ТЭО) по шкале $\mathrm{CHA}_{2} \mathrm{DS}_{2}$-VASc $(4,69 \pm 1,66$ и 4,23 1, 57, соответственно) был значимо выше, чем при пароксизмальной форме $(3,81 \pm 1,69 ; p<0,05)$. Риск геморрагических осложнений по шкале HAS-BLED был также значимо выше у пациентов с постоянной и персисти-

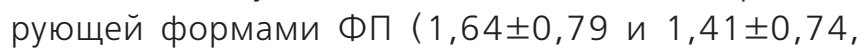
соответственно), чем при пароксизмальной форме $(1,34 \pm 0,72), p<0,05$.

Таким образом, более низкая частота назначения ОАК больным с постоянной и персистирующей фор- мами ФП, чем пациентам с пароксизмальной формой, характеризующейся меньшим риском ТЭО, является совершенно необоснованной. Этот факт может быть лишь отчасти объяснен тем, что пациентам с пароксизмами ФП уделяется больше внимания с точки зрения междисциплинарного взаимодействия, в т.ч. терапевтами, кардиологами и хирургами, с целью достижения стойкого синусового ритма и профилактики повторных пароксизмов.

Частота назначения ОАК, в т.ч. варфарина и НОAK, у больных ФП с наличием и отсутствием перенесенного ОНМК (табл. 3) статистически значимо не отличалась ( $p>0,05)$, несмотря на то, что у пациентов с анамнезом OHMK (n=702) риск развития тромбоэмболических осложнений по шкале $\mathrm{CHA}_{2} \mathrm{DS}_{2}$-VASc был статистически значимо выше $(6,14 \pm 1,34$ против 3,77士1,39; p <0,001). У перенесших ОНМК пациентов, по сравнению с не переносившими, был старше возраст $(73,7 \pm 9,5$ и 70,1 $\pm 10,9$ лет; $p<0,05)$, не было значимых различий доли женщин (58,5\% и 56,5\%; $p=0,33$ ).

В группе больных с ФП и назначением ОАК по сравнению с пациентами без назначения ОАК были меньше возраст $(69,1 \pm 10,4$ и 72,2 $\pm 10,6 ; p<0,05)$ и больше доля мужчин (46\% и 41\%, p=0,006), а доля лиц с ОНМК в анамнезе существенно не отличалась $(22,2 \%$ и 22,1\%, p=0,96). Обращает на себя внимание тот факт, что как на амбулаторном, так и на госпитальном этапах у пациентов, которым не была назначена терапия ОАК, риск тромбоэмболических осложнений

Table 2. Prescription rate of warfarin and new oral anticoagulants in patients with various forms of atrial fibrillation included in the RECVASA registers

Таблица 2. Частота назначения варфарина и НОАК у больных с различными формами ФП, включенных в регистры РЕКВАЗА

\begin{tabular}{lccc}
\hline Форма ФП & Варфарин & HОАК & Bсе ОАК \\
\hline Постоянная форма, $n(\%),(n=1422)$ & $410(28,8)^{*}$ & $202(14,2)^{*}$ & $612(43,0)^{*}$ \\
\hline Пароксизмальная форма, $n(\%),(n=880)$ & $202(23,0)$ & $217(24,6)$ & $419(47,6)$ \\
\hline Персистирующая форма, $n(\%),(n=711)$ & $197(27,7)^{*}$ & $289(40,6)^{*}$ \\
\hline *p<0,05 по сравнению с пароксизмальной формой & & $92(12,9)^{*}$ & \\
ФП - фибрилляция предсердий, НОАК - новые оральные антикоагулянты, ОАК - оральные антикоагулянты & & \\
\hline
\end{tabular}


Table 3. Prescription rate of warfarin and new oral anticoagulants in patients with or without history of acute cerebrovascular accident included in the RECVASA registers

Таблица 3. Частота назначения варфарина и НОАК больным ФП с наличием и отсутствием перенесенного ОНМК, включенных в регистры РЕКВАЗА

\begin{tabular}{lccc} 
Группа больных & Варфарин & НОАК & Все ОАК \\
\hline Больные с ФП и перенесенным ранее ОНМК, $n(\%),(n=702)$ & $181(25,8)$ & $117(16,7)$ & $298(42,5)$ \\
\hline Больные с ФП без перенесенного ранее ОНМК, $n(\%),(n=2467)$ & $636(25,8)$ & $401(16,3)$ & $1037(42,0)$ \\
\hline ОНМК - острое нарушение мозгового кровообращения, ФП - фибрилляция предсердий, НОАК - новые оральные антикоагулянты, ОАК - оральные антикоагулянты
\end{tabular}

Table 4. Comparison of the risks of thromboembolic and hemorrhagic complications in patients with atrial fibrillation with or without prescription of oral anticoagulants

Таблица 4. Сравнительная характеристика риска тромбоэмболических и геморрагических осложнений у больных с ФП с назначением/без назначения ОАК

\begin{tabular}{|c|c|c|c|c|}
\hline \multirow[t]{2}{*}{ Шкала риска } & \multicolumn{2}{|c|}{ Амбулаторный этап (n=934) } & \multicolumn{2}{|c|}{ Госпитальный этап, (n=2235) } \\
\hline & ОАК назначены & ОАК не назначены & ОАК назначены & ОАК не назначены \\
\hline $\mathrm{CHA}_{2} \mathrm{DS}_{2}$-VASC & $4,22 \pm 1,64$ & $4,71 \pm 1,56^{*}$ & $4,03 \pm 1,66$ & $4,28 \pm 1,75^{*}$ \\
\hline HAS-BLED & $1,18 \pm 0,74$ & $1,77 \pm 0,75^{*}$ & $1,33 \pm 0,74$ & $1,50 \pm 0,80^{*}$ \\
\hline
\end{tabular}

Table 5. Change in prescription rate of warfarin and new oral anticoagulants in patients with atrial fibrillation for the outpatient and hospital stages

Таблица 5. Динамика частоты назначения варфарина и НОАК больным с ФП на амбулаторном и госпитальном этапах

\begin{tabular}{|c|c|c|c|c|c|c|}
\hline \multirow[t]{2}{*}{ Регистр } & \multicolumn{2}{|c|}{$\begin{array}{l}\text { Амбулаторный этап } \\
\text { (до госпитализации) }\end{array}$} & \multicolumn{2}{|c|}{ Госпитальный этап } & \multicolumn{2}{|c|}{$\begin{array}{c}\text { Амбулаторный этап } \\
\text { (после госпитализации) }^{\text {a }}\end{array}$} \\
\hline & Варфарин & HOAK & Варфарин & HOAK & Варфарин & HOAK \\
\hline $\begin{array}{l}\text { PЕКВАЗА ФП-МосКВа, } n(\%) \\
(n=508)\end{array}$ & $145(28,5)$ & $127(25)$ & $167(32,9)$ & $261(51,4)$ & $\begin{array}{c}77 \text { из } 428 \\
(18,0)\end{array}$ & $\begin{array}{c}159 \text { из } 428 \\
(37,1)\end{array}$ \\
\hline $\begin{array}{l}\text { PЕКВАЗА ФП-Курск, } n(\%) \\
(n=502)\end{array}$ & $15(3,0)$ & $1(0,2)$ & $46(9,2)$ & $47(9,4)$ & $\begin{array}{c}37 \text { из } 308 \\
(12,0)\end{array}$ & $\begin{array}{c}30 \text { из } 308 \\
(9,7)\end{array}$ \\
\hline $\begin{array}{l}\text { РЕКВАЗА ФП-Тула, } n \text { (\%) } \\
(n=1225)\end{array}$ & $201(16,4)$ & $44(3,6)$ & $491(40,1)$ & $197(16,1)$ & - & - \\
\hline
\end{tabular}

по шкале $\mathrm{CHA}_{2} \mathrm{DS}_{2}$-VASc был статистически значимо выше $(p<0,05)$, чем у тех, кому она была назначена (табл. 4). Следует отметить, что и риск геморрагических осложнений у пациентов с ФП без терапии ОАК был значимо выше $(p<0,05)$, однако это не может быть основанием для отсутствия назначения антикоагулянтной терапии данной категории пациентов с наиболее высоким риском ТЭО.

У пациентов с ФП и назначением варфарина по сравнению с больными, которым были назначены НОАК, не было статистически значимых различий

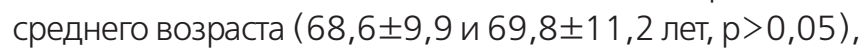
доли мужчин $(46,4 \%$ и 44,6\%; $p=0,41)$, доли лиц с ОНМК в анамнезе (22,2\% и 22,6\%; $p=0,85)$. Однако у больных с назначением варфарина были выше риск тромбоэмболических осложнений по шкале

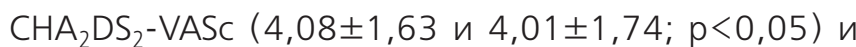
риск геморрагических осложнений по шкале $\operatorname{HAS}-\operatorname{BLED}(1,34 \pm 0,75$ и 1,29 $\pm 0,71 ; p<0,05)$.

По данным госпитальных регистров РЕКВАЗА ФП (в Москве, Курске и Туле) терапия ОАК назначалась в стационаре в 2,3 раза чаще, чем на догоспитальном этапе (54,1\% против 23,8\%; табл. 5). Частота назначения варфарина на амбулаторном этапе до госпитализации превышала таковую для НОAК во всех трех регистрах (в среднем в 2,1 раза). На госпитальном этапе частота назначения НОАК возросла в большей степени (в 2,9 раза), чем возросла частота назначения варфарина (в 1,9 раза). Средняя частота назначения ОАК в регистрах РЕКВАЗА ФП-Москва и РЕКВАЗА ФПКурск составила: на амбулаторном этапе до госпитализации - 28,5\%, в стационаре - 51,6\% и через 
Table 6. Change in use rate of warfarin and new oral anticoagulants in patients with atrial fibrillation for the outpatient stage (data for 4 years of observation in the RECVASA register; Ryazan)

Таблица 6. Динамика частоты применения варфарина и НОАК у больных с ФП на амбулаторном этапе (по данным 4-х лет наблюдения в регистре РЕКВАЗА, Рязань)

\begin{tabular}{|c|c|c|c|}
\hline Антикоагулянты & $\begin{array}{l}\text { При включении в регистр } \\
(\mathrm{n}=530)\end{array}$ & $\begin{array}{c}2 \text { года наблюдения } \\
(\mathrm{n}=432)^{\mathrm{a}}\end{array}$ & $\begin{array}{c}4 \text { года наблюдения } \\
(\mathrm{n}=371)^{\mathrm{a}}\end{array}$ \\
\hline Варфарин, n (\%) & $19(3,6)$ & $20(4,6)$ & $40(10,8) *$ \\
\hline HOAK, n (\%) & $3(0,6)$ & $8(2,2)$ & $28(7,5)^{*}$ \\
\hline Bce OAK, n (\%) & $22(4,2)$ & $28(6,5)$ & $68(18,3)^{*}$ \\
\hline \multicolumn{4}{|c|}{$\begin{array}{l}\text { адоля (\%) от числа выживших } \\
\text { *р<0,05 по сравнению с данными при включении в регистр } \\
\text { НОАК - новые оральные антикоагулянты, ОАК - оральные антикоагулянты, ФП - фибрилляция предсердий }\end{array}$} \\
\hline
\end{tabular}

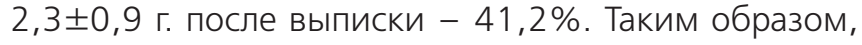
на этапе отдаленного наблюдения частота назначения OAK была в 1,3 раза меньше, чем в стационаре, но все же в 1,8 раза больше, чем до госпитализации. При учете числа умерших в стационарах в регистрах РЕКВАЗА ФП Москва и Курск (госпитальные летальные исходы были только в Курске, из 55 случаев было 2 случая на фоне приема ОАК) средняя частота назначений ОАК при выписке составила 54,3\%, что несколько больше, чем частота назначения ОАК в стационаре у всех пациентов, считая умерших (51,6\%).

Через 2 года наблюдения включенных в регистр PEКВАЗА (Рязань) пациентов с ФП частота назначения ОАК статистически не значимо увеличилась с 4,2\% до 6,5\% (табл. 6). Однако через 4 года наблюдения отмечен ее статистически значимый рост в 4,4 раза (с 4,2\% до 18,3\%; р<0,001), при этом зафиксирован рост частоты назначения как варфарина (в 3 раза), так и НОAK (в 12,5 раз; $\mathrm{p}<0,0001$ - тест Мак-Немара).

В сформированной в рамках регистра РЕКВАЗА случайной выборке 75 человек из числа 384 пациентов с ФП, выживших за период проспективного наблю-

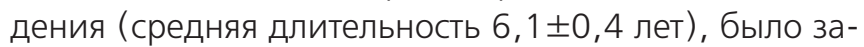
регистрировано увеличение частоты назначения ОАК с 5,3\% (n=4) на этапе включения в регистр до 22,7\% $(n=17)$, т.е. в 4,2 раза. В т.ч. частота назначения варфарина возросла с 2,7 \% $(n=2)$ до 16,0\% $(n=12)$ и НОAK - с 2,7 \% $(n=2)$ до 6,7 \% $(n=5)$, соответственно, в 6 раз и в 2,5 раза. Эти данные анализа амбулаторных карт подтверждают результаты о существенном повышении частоты назначения ОАК при ФП, полученные при телефонном опросе пациентов.

\section{Обсуждение}

Результаты обобщения данных регистров РЕКВАЗА и РЕКВАЗА ФП в 5 регионах Российской Федерации показали, что у больных с ФП, несмотря на высокий риск кардиоэмболического мозгового инсульта и других ТЭО, а также на доказанное благоприятное влияние антикоагулянтной терапии на прогноз, соблюдение принципов назначения ОАК на амбулаторно-поликлиническом и госпитальном этапах не является удовлетворительным.

Полученные данные подтверждают результаты ряда крупных международных регистровых исследований и работ отечественных авторов о недостаточной частоте назначения ОАК у больных с ФП в реальной клинической практике [7-17,24-25], хотя следует отметить, что частота назначения ОАК при ФП по данным ряда международных регистров существенно выше, чем в РФ, и составляет в странах Западной Европы 60\%-80\% [12-17].

Важно отметить полученные нами данные о том, что у больных с ФП и более высоким риском ТЭО, в частности, при наличии перенесенного ОНМК и постоянной формы ФП, частота назначения ОАК была не выше, а в целом даже ниже, чем у лиц с менее высоким риском по шкале $\mathrm{CHA}_{2} \mathrm{DS}_{2}$-VASc. Одним из возможных объяснений этого факта является то, что врачи опасаются геморрагических осложнений при назначении ОАК пациентам с высоким сердечно-сосудистым риском, с более выраженными коморбидностью и тяжестью клинического течения. Более высокая частота назначения ОАК у больных с пароксизмальной формой ФП может быть отчасти обусловлена тем, что этим пациентам уделяется большое внимание кардиологов, в отличие от более пожилых и коморбидных пациентов с постоянной формой ФП, у которых риск ТЭО выше.

Возможным путем решения данной проблемы являются повышение приверженности врачей соблюдению клинических рекомендаций (в т.ч. за счет образовательных программ), повышение приверженности больных с ФП постоянному приему антикоагулянтов, увеличение охвата диспансерным наблюдением данной категории больных, особенно, при наличии выраженной коморбидности.

Следует отметить, что в задачу данной публикации не входили детальный анализ преемственности терапии варфарином или НОАК (с учетом доли новых назначений, смены препарата, прекращения приема в ходе длительного наблюдения) и исследование при- 
верженности пациентов проводимой терапии, это предмет наших дальнейших публикаций.

\section{Заключение}

По данным регистров РЕКВАЗА и РЕКВАЗА ФП в 5 регионах Российской Федерации выявлен ряд существенных недостатков в назначении терапии ОАК. Прежде всего, это совершенно недостаточная частота назначения ОАК при ФП на госпитальном (в среднем в 42\% случаев) и, особенно, на амбулаторном этапе (всего 16\% случаев). При постоянной и персистирующей формах ФП, характеризующихся более высоким риском ТЭО, частота назначения ОАК, напротив, была статистически значимо меньше, чем при пароксизмальной. Кроме того, не выявлено существенной разницы частоты назначения ОАК при наличии и отсутствии анамнеза ОНМК (всего лишь 42,5\% и 42\%), несмотря

\section{References / Литература}

1. January C.T., Wann L.S., Calkins H., et al. 2019 AHA/ACC/HRS Focused Update of the 2014 AHA/ACC/HRS Guideline for the Management of Patients With Atrial Fibrillation. J Am Coll Cardiol. 2019;74(1):104-32. DOI:10.1016/j.jacc. 2019.01.011.

2. The 2018 European Heart Rhythm Association Practical Guide on the use of non-vitamin K antagonist oral anticoagulants in patients with atrial fibrillation: executive summary. Europace. 2018:20(8);123142. DOI:10.1093/europace/euy054.

3. Kirchhof P., Benussi S., Kotecha D., et al. 2016 ESC Guidelines for the management of atrial fibrillation developed in collaboration with EACTS. Eur Heart J. 2016;37(38):2893-962. DOI:10.1093/eurheartj/ehw210.

4. 2016 European Guidelines on cardiovascular disease prevention in clinical practice. European Heart Journal. 2016:37;2315-81. DOI:10.1093/eurheartj/ehw106.

5. Diagnosis and treatment of atrial fibrillation. 2012 RSC/RSSA/RACVS guidelines. Russian Journal of Cardiology. 2013;4(102) suppl 3:3-100 (In Russ.). [Диагностика и лечение фибрилляции предсердий. Рекомендации ВНОК, ВНОА, АССХ (2012). Российский Кардиологический Журнал. 2013:4(102) приложение 3:3-100].

6. AHA/ASA Guidelines for the Primary Prevention of Stroke. Stroke. 2014;45:3754-832. DOI:10.1161/STR.0000000000000046.

7. Camm A.J., Fox K.A., Peterson E. Challenges in comparing the non-vitamin K antagonist oral anticoagulants for atrial fibrillation-related stroke prevention. Europace. 2018:20(1);1-11. DOI:10.1093/europace/eux086

8. Komen J., Forslund T., Hjemdahl P., et al. Factors associated with antithrombotic treatment decisions for stroke prevention in atrial fibrillation in the Stockholm region after the introduction of NOACs. Eur J Clin Pharmacol. 2017:73;1315-22. DOI:10.1007/s00228-017-22890.

9. Alamneh E.A., Chalmers L., Bereznicki L.R. Suboptimal use of oral anticoagulants in atrial fibrillation: has the introduction of direct oral anticoagulants improved prescribing practices? Am J Cardiovasc Drugs. 2016:16;183-200. DOI:10.1007/s40256-016-0161-8.

10. Haim M., Hoshen M., Reges 0 ., et al. Prospective national study of the prevalence, incidence, management and outcome of a large contemporary cohort of patients with incident non-valvular atrial fibrillation. J Am Heart Assoc. 2015;4:e001486. DOI:10.1161/JAHA.114.001486.

11. Loukianov M.M., Yakushin S.S., Martsevich S.Y., et al. Cardiovascular Diseases and Drug Treatment in Patients with the History of Cerebral Stroke: Data of the Outpatient Registry REGION. Ration Pharmacother Cardiol. 2018;14(6):879-86 (In Russ.) [Лукьянов М.М., Якушин С.С., Марцевич С.Ю., и др. Сердечно-сосудистые заболевания и их медикаментозное лечение у больных, перенесших острое нарушение мозгового кровообращения: данные амбулаторного регистра РЕГИОН. Рациональная Фармакотерапия в Кардиологии. 2018;14(6):879-86] DOI:10.20996/18196446-2018-14-6-879-886

12. Huisman M.V., Rothman K.J., Paquette M., et al. The changing landscape for stroke prevention in AF: findings from the GLORIA-AF Registry Phase 2. J Am Coll Cardiol. 2017:69:777-85. DOI:10.1016/j.jacc.2016.11.061.

13. De Caterina R., Renda G., Sangiuolo R., et al. Management of thromboembolic risk in patients with atrial fibrillation in Italy: baseline data from the PREFER in AF European Registry. G Ital Cardiol (Rome). 2014;2:99-109. DOI:10.1714/1424.15779.

14. Steinberg B.A., Gao H., Shrader P., et al. International trends in clinical characteristics and oral anticoagulation treatment for patients with atrial fibrillation: Results from the GARFIELD-AF, ORBIT-AF I, and ORBIT-AF II registries. Am Heart J. 2017;194:132-140. DOl:10.1016/j.ahj.2017.08.011. на то, что риск ТЭО значительно выше у лиц, перенесших ОНМК. Существенной проблемой является также то, что терапия ОАК (в т.ч. варфарином и НОАК) назначается в целом пациентам с ФП и более низким риском ТЭО, чем у тех больных, которым она не была назначена. Позитивным фактом является значительное, хотя и недостаточное, повышение частоты назначения ОАК (в большей степени НОАК, чем варфарина) больным с ФП на амбулаторно-поликлиническом этапе по данным длительного проспективного наблюдения (длительностью от 2 до 6 лет).

Конфликт интересов. Все авторы заявляют об отсутствии потенциального конфликта интересов, требующего раскрытия в данной статье.

Disclosures. All authors have not disclosed potential conflicts of interest regarding the content of this paper.

15. Lip G.Y., Laroche C., Dan G.A., et al. "Real-World" Antithrombotic Treatment in Atrial Fibrillation: The EORP-AF Pilot Survey. The American Journal of Medicine 2014;127(6):519-29. DOI:10.1016/j.amjmed.2013.12.022

16. Haeusler K.G., Gerth A., Limbourg T., et al. Use of vitamin K antagonists for secondary stroke prevention depends on the treating healthcare provider in Germany - results from the German AFNET registry. BMC Neurology. 2015;15:129. DOI:10.1186/s12883-015-0371-8.

17. Lip G.Y., Nieuwlaat R., Pisters R., et al. Refining clinical risk stratification for predicting stroke and thromboembolism in atrial fibrillation using a novel risk factor-based approach: the Euro Heart Survey on atrial fibrillation. Chest. 2010;137:263-72.

18. Loukianov M.M., Boytsov S.A., Yakushin S.S., et al. Diagnostics, treatment, associated cardiovascular and concomitant non-cardiac diseases in patients with diagnosis of "atrial fibrillation" in real outpatient practice (according to data of registry of cardiovascular diseases, RECVASA). Ration Pharmacother Cardiol. 2014;10(4):366-77 (In Russ.) [Лукьянов М.М., Бойцов С.А., Якушин С.С. и др. Диагностика, лечение, сочетанная сердечно-сосудистая патология и сопутствующие заболевания у больных с диагнозом «фибрилляция предсердий» в условиях реальной амбулаторно-поликлинической практики (по данным регистра кардиоваскулярных заболеваний РЕКВАЗА). Рациональная Фармакотерапия в Кардиологии. 2014;10(4):366-77]. DOI:10.20996/ 1819-6446-2014-10-4-366-377

19. Stepina E.V., Loukianov M.M., Bichurina M.A., et al. Oral Anticoagulants in Ambulatory and In-Hospital Treatment of Patients with Atrial Fibrillation Associated with Hypertension, Ischemic Heart Disease and Chronic Heart Failure: Data from Hospital Registry RECVASA-CLINIC. Rationa Pharmacotherapy in Cardiology. 2017;13(2):146-54 (In Russ.) [Степина Е.В., Лукьянов М.М., Бичурина М.А. с др. Терапия оральными антикоагулянтами у больных с фибрилляцией предсердий в сочетании с артериальной гипертонией, ишемической болезнью сердца, хронической сердечной недостаточностью на госпитальном и амбулаторном этапах лечения по данным регистра РЕКВАЗА-КЛИНИКА. Рациональная Фармакотерапия в Кардиологии. 2017;13(2):146-54]. DOI:10.20996/1819-6446-2017-13-2-146-154.

20. Yakusevich V.V., Pozdnyakova E.M., Yakusevich V.M., et al. An outpatient with atrial fibrillation: key features. THE first data of REKVAZA FP - YAROSLAVL register. Rational Pharmacotherapy in Cardiology. 2015;11 (2):149-52. (In Russ). [Якусевич В.В., Позднякова Е.М., Якусевич В.Вл. С др. Амбулаторный пациент с фибрилляцией предсердий: основные характеристики. Первые данные регистра РЕКВАЗА ФП - Ярославль. Рациональная Фармакотерапия в Кардиологии 2015;11(2):149-52] DOI:10.20996/1819-6446-2015-11-2-149-152.

21. Mikhin V.P., Maslennikova Y.V., Lukyanov M.M., et al. Drug therapy in patients with coronary heart disease in combination with atrial fibrillation in real medical practice (results of RECVASA AF-Kursk registry). Kursk Scientific and Practical Bulletin "Man and His Health". 2017;(2):49-54. (In Russ.). [Михин В.П., Масленникова Ю.В., Лукьянов М.М. и др. Медикаментозная терапия больных ишемической болезнью сердца в сочетании с фибрилляцией предсердий в реальной медицинской практике (результаты регистра РЕКВАЗА ФП-Курск). Курский Научно-практический Вестник «Человек и его здоровье». 2017;(2):4954. DOI:10.21626/vestnik/2017-2/09.

22. Valiakhmetov M.N., Gomova T.A., Loukianov M.M., et al. Patients with Atrial Fibrillation in Multidisciplinary Hospital: Structure of Hospitalization, Concomitant Cardiovascular Diseases and Drug Treatment (Data of RECVASA AF - Tula Registry). Rational Pharmacotherapy in Cardiology. 2017;13(4):484-94 (In Russ). [Валиахметов М.Н., Гомова Т.А., Лукьянов М.М. и др. Больные с фибрилляцией предсердий в условиях многопрофильного стационара: структура госпитализации, сочетанные сердечно-сосудистые заболевания и медикаментозная терапия (данные регистра РЕКВАЗА ФП-Тула). Рациональная Фармакотерапия в Кардиологии. 2017;13(4):48494.] DOI:10.20996/1819-6446-2017-13-4-484-494. 
23. Loukianov M.M., Martsevich S.Y., Yakushin S.S., et al. The Control of International Normalised Ratio in Patients with Atrial Fibrillation Treated with Warfarin in Outpatient and Hospital Settings: Data from RECVASA Registries. Rational Pharmacotherapy in Cardiology. 2018;14(1):34-40 (In Russ.) [Лукьянов М.М., Марцевич С.Ю., Якушин С.С. и др. Контроль показателя международного нормализованного отношения на фоне терапии варфарином у больных с фибрилляцией предсердий в амбулаторной и госпитальной практике (данные регистров РЕКВАЗА). Рациональная Фармакотерапия в Кардиологии. 2018;14(1):34-40]. DOI:10.20996/1819-64462018-14-1-34-40.
24. Martsevich S.Y., Navasardyan A.R., Kutishenko N.P., et al. The assessment of compliance to the use of new oral anticoagulants in patients with atrial fibrillation according to the PROFILE register. Rational Pharmacotherapy in Cardiology. 2014;10(6):625-30 (In Russ.) [Марцевич С.Ю., Навасардян А.Р., Кутишенко Н.П. и др. Оценка приверженности к приему новых пероральных антикоагулянтов у пациентов с фибрилляцией предсердий по данным регистра ПРОФИЛЬ. Рациональная Фармакотерапия в Кардиологии. 2014;10(6):625-30]. DOI:10.20996/1819-6446-2014-10-6625-630

25. Moiseev S.V. Anticoagulation therapy adherence: issues and solutions. Klin Pharmakol and Ther 2014;23(4):23-8. (In Russ.). [Моисеев С.В. Приверженность кантикоагулянтной терапии: проблемы и пути решения. Клиническая Фармакология и Терапия. 2014;23(4):23-8].

\section{About the Authors:}

Mikhail M. Loukianov - MD, PhD, Head of Department of Clinical Cardiology and Molecular Genetics, National Medical Research Center for Preventive Medicine

Sergey Yu. Martsevich - MD, PhD, Professor, Head of Department of Preventive Pharmacotherapy, National Medical Research Center for Preventive Medicine

Oxana M. Drapkina - MD, PhD, Professor, Corresponding Member of the Russian Academy of Sciences, Director of National Medical Research Center for Preventive Medicine

Sergey S. Yakushin - MD, PhD, Professor, Head of Chair of Hospital Therapy, Ryazan State Medical University named after Academician I.P. Pavlov

Alexander N. Vorobyev - MD, PhD, Associate Professor, Chair of Hospital Therapy, Ryazan State Medical University named after Academician I.P. Pavlov

Kristina G. Pereverzeva - MD, PhD, Assistant, Chair of Hospital Therapy, Ryazan State Medical University named after Academician I.P. Pavlov

Alexander V. Zagrebelnyy - MD, PhD, Senior Researcher, Department of Preventive Pharmacotherapy, National Medical Research Center for Preventive Medicine

Vladimir Val. Yakusevich - MD, PhD, Professor, Chair of Clinical Pharmacology, Yaroslavl State Medical University

Vladimir VI. Yakusevich - MD, Researcher, Chair of Clinical Pharmacology, Yaroslavl State Medical University

Ekaterina M. Pozdnyakova - MD, Researcher, Department of Clinical Pharmacology, Yaroslavl State Medical University Tatiana A. Gomova - MD, PhD, Deputy Chief Physician for General Issues, Tula Regional Clinical Hospital Marat N. Valiakhmetov - MD, Acting Chief Physician for Therapeutic Care, Tula Regional Clinical Hospital Elena E. Fedotova - MD, Cardiologist, Clinical and Diagnostic Center, Tula Regional Clinical Hospital

Vadim P. Mikhin - MD, PhD, Professor, Head of Chair of Internal Medicine №2, Kursk State Medical University

Yulia V. Maslennikova - MD, PhD, Chair of Internal Medicine №2, Kursk State Medical University

Elena Yu. Andreenko - MD, PhD, Senior Researcher, Department of Clinical Cardiology and Molecular Genetics, National Medical Research Center for Preventive Medicine

Vladislav G. Klyashtorny - PhD (in Biology), Researcher, Laboratory of Biostatistics, National Medical Research Center for Preventive Medicine

Egor V. Kudryashov - Programmer, Laboratory of Biostatistics, National Medical Research Center for Preventive Medicine Elena Yu. Okshina - MD, PhD, Senior Researcher, Department of Clinical Cardiology and Molecular Genetics, National Medical Research Center for Preventive Medicine

Marina A. Panagopulu - MD, cardiologist, National Medical Research Center for Preventive Medicine

Sergey A. Boytsov - MD, PhD, Professor, Corresponding Member of the Russian Academy of Sciences, General Director of National Medical Research Center of Cardiology
Сведения об авторах:

Лукьянов Михаил Михайлович - К.м.Н., руководитель отдела клинической кардиологии и молекулярной генетики, НМИЦ ПМ

Марцевич Сергей Юрьевич - Д.м.Н., профессор, руководитель отдела профилактической фармакотерапии, НМИЦ ПМ

Драпкина Оксана Михайловна - Д.м.Н., профессор, чл.корр. РАН, директор НМИЦ ПМ

Якушин Сергей Степанович - Д.м.н., профессор, зав. кафедрой госпитальной терапии, Рязанский ГМУ им. академика И.П. Павлова

Воробьев Александр Николаевич - К.м.Н., доцент, кафедра поликлинической терапии и профилактической медицины Рязанский ГМУ им. академика И.П. Павлова

Переверзева Кристина Геннадьевна - К.М.Н., ассистент, кафедра госпитальной терапии, Рязанский ГМУ им. академика И.П. Павлова

Загребельный Александр Васильевич - К.М.Н., С.Н.С., отдел профилактической фармакотерапии, НМИЦ ПМ Якусевич Владимир Валентинович - Д.м.Н., профессор кафедра клинической фармакологии, Ярославский ГМУ Якусевич Владимир Владимирович - Н.С., кафедра клинической фармакологии, Ярославский ГМУ

Позднякова Екатерина Михайловна - Н.С., кафедра клинической фармакологии, Ярославский ГМУ

Гомова Татьяна Александровна - К.м.Н., заместитель главного врача по общим вопросам, Тульская областная клиническая больница

Валиахметов Марат Нафизович - исполняющий обязанности главного врача Городская больница №3 г. Тулы

Федотова Елена Евгеньевна - врач-кардиолог, Тульская областная клиническая больница

Михин Вадим Петрович - д.м.н., профессор, зав. кафедрой внутренних болезней №2, Курский ГМУ

Масленникова Юлия Вениаминовна - К.м.Н., кафедра внутренних болезней №2, Курский ГМУ

Андреенко Елена Юрьевна - С.Н.С., отдел клинической кардиологии и молекулярной генетики, НМИЦ ПМ

Кляшторный Владислав Георгиевич - К.б.Н., Н.С., лаборатория биостатистики, НМИЦ ПМ

Кудряшов Егор Николаевич - программист, лаборатория биостатистики, НМИЦ ПМ

Окшина Елена Юрьевна - С.Н.С., отдел клинической кардиологии и молекулярной генетики, НМИЦ ПМ Панагопулу Марина Ареслановна - врач-кардиолог, НМИЦПМ

Бойцов Сергей Анатольевич - Д.М.Н., профессор, чл.корр. РАН, директор НМИЦ Кардиологии 